\title{
Perinatal Outcome of Fetal Echogenic Bowel: A Single-Center Retrospective Cohort Study
}

\author{
Hidayet SAL'1, Erhan Huseyin COMERT'1, Yasin Semih EKICI', Turhan ARAN1 \\ Trabzon, Turkey
}

\begin{abstract}
OBJECTIVE: The aim of this study is to evaluate perinatal outcome of fetal echogenic bowel.

STUDY DESIGN: In this retrospective cohort study, fetuses with echogenic bowel diagnosed and followed in our center between 2013-2017 were included. Fetuses and infants were evaluated in terms of antenatal comorbidities and postnatal persistent diseases. Infants were followed-up to June 2018 from time of diagnosis. Demographic questionnaire and face to face interview were used to obtain data including immune system diseases and respiratory system pathologies in infants.
\end{abstract}

RESULTS: A total of 100 fetuses with echogenic bowel were included in the study. Fetal aneuploidy was detected in $7(7 \%)$ cases. Trisomy 21 was the most common aneuploidy and identified in $4(4 \%)$ cases. Other chromosomal disorders were tetrasomy 12p (1\%), 69XXX (1\%) and $46 \mathrm{XX}, t(2,22)(9 q 9)(1 \%)$. A fetal echogenic bowel was associated with major congenital malformations in 25 (\%25) cases. Cardiac abnormality was the most prevalent (\%7). First and second trimester vaginal bleeding history was found in 5 pregnant women. In 3 case with isolated echogenic bowel (no congenital malformation and aneuploidy), lactose intolerance, celiac disease, and non-obstructive hydrocephalus were diagnosed in early childhood.

CONCLUSION: Isolated fetal echogenic bowel which can be considered as a soft marker for aneuploidy may be associated with lactose intolerance and celiac disease. Further clinical studies are warranted to evaluate this relationship.

Keywords: Aneuploidy, Echogenic bowel, Perinatal outcome

Gynecol Obstet Reprod Med 2021;27(1):1-5

\section{Introduction}

Isolated minor ultrasonographic anomalies are evaluated as a variant of normal fetal anatomy in the second trimester fetal ultrasonography (1-3). Hyperechogenic bowel (HEB) is one of the minor anomalies and was first described by Lince et al.(4). Fetal bowel is observed echogenic in ultrasonogra-

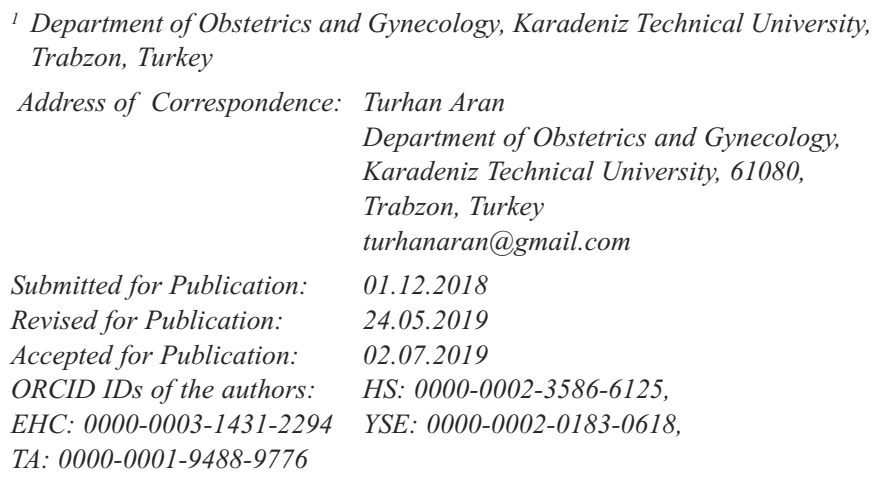

\begin{tabular}{c|c}
\hline Quick Response Code: & Access this article online \\
\cline { 2 - 2 } & Website: www.gorm.com.tr \\
e- mail: info@gorm.com.tr \\
\cline { 2 - 3 }
\end{tabular}

How to cite this article: Sal H. Comert EH. Ekici YS. Aran T. Perinatal Outcome of Fetal Echogenic Bowel: A Single-Center Retrospective Cohort Study. Gynecol Obstet Reprod Med 2021;27(1):1-5 phy due to meconium accumulation after $16^{\text {th }}$ week of pregnancy $(5,6)$. The echogenicity of the fetal bowel is often compared with bone tissue echogenicity as bright as nearby bone on the lowest gain setting $(7,8)$.

Hyperechogenic bowel is observed between $0.6 \%$ and $1.4 \%$ in the second trimester ultrasonography $(8-10)$. It is predicted that perinatal complications (intrauterine growth restriction, intraamniotic hemorrhage, perinatal death, karyotype anomalies, cytomegalovirus, parvovirus, toxoplasmosis, fetal metabolic diseases, small bowel obstruction, bowel agenesis, observer error, etc.) can be seen in $4-20 \%$ of pregnancies $(11,12)$. In the second trimester, in $60 \%$ of fetuses with $\mathrm{HEB}$, no anomaly is seen in the postnatal period, although $40 \%$ karyotype anomaly, intrauterine growth restriction (IUGR) or perinatal death can be seen $(7,8,10,13)$. HEB should be evaluated routinely on second trimester sonography as it is accompanied by anomalies leading to perinatal morbidity and mortality.

The aim of this study was to evaluate the perinatal outcomes of pregnancies with fetal HEB.

\section{Material and Method}

This retrospective cohort study was approved by the local ethics committee (02.02.2018-18). This study was conducted 
on pregnant women who age 22-44 years old in the second or third trimester, who were referred to our high-risk pregnancy unit because of fetal HEB detected on ultrasound; between January 2013 and December 2017. All cases with HEB in which either combined screening test or triple tests were performed were included in the study. The detailed fetal anatomic scan was performed to reveal associated abnormalities and malformations. Sonographic evaluations were performed by at least two perinatologists, who were experienced in maternalfetal medicine in order to prevent misdiagnosis. Ultrasonography was performed by using the 2-7 MHz abdominal probes of the sonographic system of Voluson Expert (General Electric Healthcare Systems, Austria). During the ultrasonographic evaluation, the fetus; head, face, neck, thoracic cavity (four-chamber view of the heart and outflow tract), abdominal cavity, extremities (including hands and feet), spinal cord, long bones, and genital region were evaluated. We reported abnormalities of each organ. Cytogenetic evaluations were performed on amniocentesis samples by conventional karyotype analysis at all patients. Amniotic cells were cultured after amniocentesis. 20 metaphase phases were expected in at least 5 cultures. Major chromosomal defects identified in seven cases. All infants were followed-up to June 2018 from time of diagnosis. Demographic questionnaire and face to face interview were used to obtain data.

All procedures performed in studies involving human participants were in accordance with the ethical standards of the institutional and/or national research committee and with the 1964 Helsinki declaration and its later amendments or comparable ethical standards (14).

The consent for using data was obtained from all individual participants included in the study.

\section{Results}

A total of 100 fetuses with HEB that with isolated and nonisolated were included in the study. The mean maternal age of all cases was 32.7 years and the mean diagnosis gestation week of HEB was 17 weeks. The median gravida was 3 , the parity was 2 , and the mean birth weight was $3244 \pm 314$ gram. Three of the patients $(3 \%)$ included in the study were pregnant with assisted reproductive techniques (ART) and the rest were spontaneous pregnancies. All of the pregnancies with ART were in the HEB with major anomalies. The screening test was reported as a high-risk in $18(60 \%)$ patients and also in other 12 $(40 \%)$ had advanced maternal age in isolated HEB. Five cases had vaginal bleeding that three of them were in the first trimester and two in the second trimester in the prenatal period.

Major chromosomal defects identified in $(7 \%)$ cases (Table I). One (1\%) of them were identified as $46 \mathrm{XX}, \mathrm{t}(2,22)$ (9q9) in isolated HEB and $6(6 \%)$ in echogenic bowel with major anomalies. In HEB with major anomalies, four of six chromosomal disorders were reported as trisomy 21 (4\%), one as tetrasomy $12 \mathrm{p}(1 \%)$, and one as $69 \mathrm{XXX}(1 \%)$. In the antenatal ultrasonography, there were seven patients (7\%) having cardiac pathology (two left heart hypoplasia, three VSD, one truncus arteriosus, one tricuspid prolapse), two (2\%) had a urinary system anomalies, seven $(7 \%)$ had neural tube defects (three Arnold-Chiari syndrome, two cases anencephaly, one holoprosencephaly, one Dandy-Walker malformation), two (2\%) had hydrops fetalis, two $(2 \%)$ had gastrointestinal system anomaly (one case with absence of a gastric bubble, one case with intestinal dilatation), three patients (4\%) had skeleton anomaly (one club foot, one club foot and clenched hand, one brachycephaly) at this study. In two (2\%) of the patients, IUGR was present at the time of the first visit. Ten $(10 \%)$ of the cases were terminated due to severe malformations with the request of the family.

There were pelviectasis in 16 cases $(16 \%)$, echogenic cardiac focus in 17 cases $(17 \%)$, and choroid plexus cyst in 17 cases $(17 \%)$. Nasal bone hypoplasia was detected in seven cases $(7 \%)$, short femur length was detected in two cases $(2 \%)$. In the first trimester, there were increased nuchal translucency in three cases $(3 \%)$. Bilateral uterine artery notching was detected in two cases $(2 \%)$ in Doppler ultrasonography.

Sixty-one patients of all cases were reached by phone in

Table 1: This table shows number and additional anomalies of cases with chromosomal disorders at study

\begin{tabular}{lcl}
\hline Genetic results & Number of cases & Additional anomalies $^{*}$ \\
\hline $\begin{array}{l}\text { Tetrasomy 12p } \\
\text { (Pallister-Killian syndrome ) }\end{array}$ & 1 & Short femur length and short humerus length \\
$\begin{array}{l}\text { Trisomy } 21 \\
\text { (Down syndrome) }\end{array}$ & 4 & No anomalies ${ }^{* *}$ \\
69 XXX & 1 & Bilateral choroid plexus cyst, brachycephaly, polycystic \\
$($ Partial mole pregnancy) & & $\begin{array}{l}\text { kidney disease, pelviectasis } \\
46 \text { XX, t (2,22) (9q9) } \\
(\text { Paternal translocation })\end{array}$ \\
\hline
\end{tabular}

*Additional structural anomalies in ultrasonography. ${ }^{* *}$ This cases are in HEB isolated group. 
the postnatal follow-up. Forty-seven of them did not develop any disease after childbirth. Three cases $(4.9 \%)$ with renal disease, one patient with cardiac disease $(1.6 \%)$, two cases with skeletal anomaly (3.2\%), and four cases with neural tube defects $(6.5 \%)$ were present in the postpartum period. There were no permanent respiratory system diseases in the postnatal follow-up. Postnatal follow-up revealed no immunodeficiency. One patient in ventricular septal defect with HEB had lactose intolerance during postnatal follow-up. In the postnatal period, in isolated HEB, two cases had a food allergy, one of them had lactose intolerance and one had celiac disease. Thus, food allergy was found in three cases $(4.9 \%)$ in the study. Hydrocephalus developed in two (2\%) patient after the detection of HEB.

\section{Discussion}

Isolated HEB should be evaluated as a minor marker as a variant of normal. Minor anomalies are considered as fetal echogenic intracardiac focus, choroidal plexus cyst, isolated renal pelviectasis, HEB (15). Fetal bowels are compared with bone tissue echogenicity (6-8), but some authors have recommended comparison with fetal solid organs [liver $(9,10)$, lung (16)]. According to the classification of ultrasonic echogenicity determined to minimize observer error in HEB evaluation; grade 0: normal, grade 1: increased echogenicity, but less echogenic from bone, grade 2: equal echogenicity to bone, grade 3: echogenic than bone, was divided into 4 groups (17).

Hyperechogenic bowel can be isolated or seen in many diseases. HEB can be observed in $0.1-1.8 \%$ of normal pregnancies (9). HEB is defined as a non-specific prenatal marker in cases such as cystic fibrosis, chromosomal aneuploidies, small bowel obstruction, Hirschsprung's disease, intestinal atresia, intraamniotic hemorrhage and oligohydramnios $(9,18)$.

Isolated fetal HEB does not require additional research, however, in study in 2018, data from the Ministry of Health of Israel between January 2013 and September 2016 were examined and cases with chromosomal microarray analysis were retrospectively evaluated. Chromosomal microarray analysis in 9272 pregnant women was compared with the chromosome results of 5541 pregnant women with normal ultrasonographic findings. According to 103 chromosomal microarray analysis performed for isolated HEB, 2 samples $(1.94 \%)$ were abnormal (47, XYY and 16p11.2 duplication). According to the results of this study, it was found that isolated HEB pregnancies had no risk increase for abnormal chromosomal analysis compared to fetuses without sonographic anomaly findings. In the management of such pregnancies, it is suggested that chromosomal evaluation (invasive chromosomal examination) should not be different from pregnancies with normal ultrasonography (13). These results confirm that fetal HEB is one of the minor markers. The data of our study confirmed this information and one of 30 patients had a chromosomal disease.
In a study, $7 \%$ of fetuses with down syndrome were associated with isolated HEB. Despite this high rate, HEB is not a specific marker for trisomy 21 but can be considered as a soft marker according to the literature $(9,10,19)$. In a meta-analysis performed in North America, 230 cases were evaluated and in $60 \%$ of all cases, there was not the additional anomaly in the postnatal follow-up. Karyotype abnormalities, intrauterine growth, and perinatal mortality rates were high in the diseased group (7-10,13). Sex chromosomal abnormalities such as turner syndrome were determined among the aneuploidies, mostly trisomy 21 . The frequency of aneuploidy ranged from $3 \%$ to $27 \%$. Trisomy 13,18 , Turner syndrome and triploidy are also observed in chromosomal diseases $(9,19)$. In a study of the perinatology clinical data of Zekai Tahir Burak Training and Research Hospital between 2007 and 2010 were evaluated ultrasonographic findings of fetuses with 177 aneuploidies in the second trimester. HEB was detected in $4.1 \%$ of fetuses with trisomy 21 and in $13.3 \%$ of fetuses with trisomy 18 (20).

In our study, four cases (4\%) with trisomy 21 were detected in HEB isolated group. There is one case 69XXX, one case tetrasomy $12 \mathrm{p}$, one case $46 \mathrm{XX}, t(2,22)(9 \mathrm{q} 9)$ (total seven cases (7\%) chromosomal anomaly), however, we found normal karyotype analysis of all remaining cases. The patient with 69XXX in diagnosed with HEB in the second trimester was evaluated as partial molar pregnancy histopathologically after suction curettage. We evaluated the case of tetrasomy $12 \mathrm{p}$ as Pallister-Killian syndrome. $46 \mathrm{XX}, t(2,22)(9 \mathrm{q} 9)$ determined that the fetus was caused by paternal heredity after chromosomal analysis of the parents. Thus, in our study, it was concluded that in fetuses with HEB, trisomy 21 can be used as a soft marker to determine the risk, in cases with isolated cases no additional examination is required, and karyotype analysis should be performed in the accompanying anomalies. It is necessary to take a collective decision about chromosomal sampling by interviewing with the family in isolated HEB. It is recommended to give information about trisomy 21 to pregnant women who do not have bleeding in the antenatal period.

Recently a study had evaluated 422 fetuses with HEB and 59 (14\%) patients were developed IUGR (21). Blood flow away from the intestine was thought to cause this condition (22). Ecevit et al. examined three cases who developed necrotizing enterocolitis with the presence of end-diastolic flow loss or reverse flow in the umbilical artery with HEB in the early neonatal period. Necrotizing enterocolitis development secondary to chronic hypoxia in these fetuses was reported earlier than the expected day, as the beginning first day of life (23). In our study, we detected two IUGR cases $(2 \%)$ and detected gastrointestinal system anomalies (absence of a gastric, intestinal dilatation) in these cases $(2 \%)$.

Hyperechogenic bowel is observed between $50-70 \%$ in cystic fibrosis $(1,24)$. Diffuse echogenicity, calcified focal 
echogenicity, hyperechogenic mass or bowel enlargement can view in bowel ultrasonography in cystic fibrosis. This image is thought to be due to the change of meconium density by pancreatic enzyme abnormalities in cystic fibrosis $(11,25,26)$. Cystic fibrosis is observed in $0,8-13,3 \%$ of HEB fetuses (12, 26-28). Cystic fibrosis cases were not found in our patients with postnatal follow-up.

Hyperechogenic bowel can be also associated with intrauterine infections (cytomegalovirus, toxoplasma, and parvovirus) and metabolic diseases (29). HEB can be observed in $0-10 \%$ of congenital infections (27). Cytomegalovirus infection is seen as the most common infection (12). In the thalassemia, HEB is a rare disease. The hypoxic-anemic process caused by bowel wall edema cause HEB at thalassemia (28). None of our cases had a prenatal infection.

In case of intra-amniotic hemorrhage, it is thought that hemosiderin pigment, which is swallowed from the amniotic fluid of fetus, may cause an increase in echogenicity of the bowel. In a study, $3.1 \%$ of the amniotic fluid was shown to be extremely contaminated with blood (12). In another study in which 28 fetuses without HEB were evaluated before intrauterine transfusion, ultrasonographic bowel echogenicity was evaluated 12 hours and 2 weeks after the procedure. HEB was observed 12 hours after the procedure in $25 \%$ of cases and $18 \%$ after 2 weeks $(21,30)$. In our study, vaginal bleeding was seen in 10 cases during pregnancy. There was no statistically significant difference between the isolated HEB and HEB with structural anomalies. We found the distribution equal.

According to the data obtained in our study, it can say that isolated HEB is more prone to food allergy than HEB fetuses with structural anomalies. It should be kept in mind that allergic diseases such as celiac disease and lactose intolerance may occur in the postnatal period in isolated HEB. Further studies are needed on this subject. Isolated HEB should be evaluated as a minor marker as a variant of normal. HEB may be associated with additional diseases. Confirmation of such associations by prenatal chromosomal diagnostic test minimizes the risks of perinatal complications.

Authorship declaration: All authors listed meet the authorship criteria according to the latest guidelines of the International Committee of Medical Journal Editors and all authors are in agreement with the manuscript.

The authors declare that they have no conflict of interest.

Financing: The authors disclosed that they did not receive any grant during conduction or writing of this study.

Ethical approval: All procedures performed in studies involving human participants were in accordance with the ethical standards of the institutional and/or national research committee and with the 1964 Helsinki declaration and its later amendments or comparable ethical standards.

The consent for using data was obtained from all individual participants included in the study.
Authors' Contributions: HS, TA: The acquisition, analysis and interpre-tation of data were performed. TA: The con-ception and design of the study were performed, HS, YSE, EHC, TA: Drafted the article or revising it critically for important intellectual content. All authors were responsible for the final approval of the version to be submitted.

\section{References}

1. Sukupova M. Dhaifalah I. Adamik Z. Havalova J. Hyperechogenic fetal bowel as a marker of fetal cystic fibrosis. Ceska Gynekol. 2015;80(1):20-4.

2. Catania VD. Taddei A. Pellegrino M. De Marco EA. Merli L. Manzoni C. et al. Hyperechogenic Bowel: Etiologies, Management, and Outcome according to Gestational Age at Diagnosis in 279 Consecutive Cases in a Single Center. Eur J Pediatr Surg. 2017;27(1):109-15. doi: 10.1055/s-0036-1597671.

3. Masini G, Maggio L, Marchi L, Cavalli I, Ledda C, Trotta $\mathrm{M}$, et al. Isolated fetal echogenic bowel in a retrospective cohort: The role of infection screening. Eur J Obstet Gynecol Reprod Biol. 2018;231:136-41.

4. Lince DM, Pretorius DH, Manco-Johnson ML, Manchester D, Clewell WH. The clinical significance of increased echogenicity in the fetal abdomen. AJR Am J Roentgenol. 1985;145(4):683-6.

5. Buiter HD, Holswilder-Olde Scholtenhuis MA, Bouman $\mathrm{K}$, van Baren R, Bilardo CM, Bos AF. Outcome of infants presenting with echogenic bowel in the second trimester of pregnancy. Arch Dis Child Fetal Neonatal Ed. 2013;98(3):F256-9.

6. Ekin A. Gezer C. Taner CE. Ozeren M. The effect of associated structural malformations in the prediction of chromosomal abnormality risk of fetuses with echogenic bowel. J Matern Fetal Neonatal Med. 2016;29(1):41-5. doi: 10.3109/14767058.2014.986091.

7. De Oronzo MA. Hyperechogenic fetal bowel: an ultrasonographic marker for adverse fetal and neonatal outcome? J Prenat Med. 2011;5(1):9-13.

8. Jackson CR. Orford J. Minutillo C. Dickinson JE. Dilated and echogenic fetal bowel and postnatal outcomes: a surgical perspective. Case series and literature review. Eur J Pediatr Surg. 2010;20(3):191-3. doi:10.1055/s-00301247523.

9. Miller ME. Allen VM. Brock JK. Incidence and Carrier Frequency of CFTR Gene Mutations in Pregnancies With Echogenic Bowel in Nova Scotia and Prince Edward Island. J Obstet Gynaecol Can. 2018;40(7):896-902. doi: 10.1016/j.jogc.2017.11.021.

10. Ronin C. Mace P. Stenard F. Loundou A. Capelle M. Mortier I. et al. Antenatal prognostic factor of fetal echogenic bowel. Eur J Obstet Gynecol Reprod Biol. 2017;212:166-70. doi: 10.1016/j.ejogrb.2017.01.060.

11. Mailath-Pokorny M. Klein K. Klebermass-Schrehof K. 
Hachemian N. Bettelheim D. Are fetuses with isolated echogenic bowel at higher risk for an adverse pregnancy outcome? Experiences from a tertiary referral center. Prenat Diagn. 2012;32(13):1295-9. doi: 10.1002/pd.3999.

12. Nigro G. Adler SP. Gatta E. Mascaretti G. Megaloikonomou A. La Torre R. et al. Fetal hyperechogenic bowel may indicate congenital cytomegalovirus disease responsive to immunoglobulin therapy. J Matern Fetal Neonatal Med. 2012;25(11):2202-5. doi: 10.3109/ 14767058.2012.684111.

13. Singer A. Maya I. Koifman A. Nasser Samra N. Baris HN. Falik-Zaccai T. et al. Microarray analysis in pregnancies with isolated echogenic bowel. Early Hum Dev. 2018;119:25-8. doi: 10.1016/j.earlhumdev.2018.02.014.

14. World Medical Association. World Medical Association Declaration of Helsinki: ethical principles for medical research involving human subjects. JAMA. 2013;310 (20): 2191-4. doi: 10.1001/jama.2013.281053.

15. Woodfield C. Obstetrical Ultrasonography in the Second Trimester. In: Torigian D. Ramchandani P. editor. Radiology Secrets Plus. $4^{\text {th }}$ ed. Philadelphia: Elsevier; 2016. p. 592-601.

16. Bashiri A. Burstein E. Hershkowitz R. Mazor M. Fetal echogenic bowel by ultrasound: what is the clinical significance? Harefuah. 2007;146(12):964-9, 96-7.

17. Maillet L. Rudigoz RC. Buffin R. Massardier J. Gaucherand P. Huissoud C. Neonatal outcome of fetal hyperechogenic bowel. Gynecol Obstet Fertil. 2014;42(6): 383-6. doi: 10.1016/j.gyobfe.2014.01.006.

18. Iruretagoyena JI. Bankowsky H. Heiser T. Birkeland L. Grady M, Shah D. Outcomes for fetal echogenic bowel during the second trimester ultrasound. J Matern Fetal Neonatal Med. 2010;23(11):1271-3. doi: 10.3109/ 14767050903551442 .

19. Rink BD. Norton ME. Screening for fetal aneuploidy. Semin Perinatol. 2016;40(1):35-43. doi: 10.1053/j.semperi.2015.11.006.

20. Celen SO A. Dover N. Aydogan P. Mollamahmudoglu L. Danısman N. Second Trimester Ultrasonographic Findings in Aneuploidic Fetuses: Zekai Tahir Burak Women's Health Education and Research Hospital Perinatology Clinic Experiences. Cumhuriyet Med J. 1305-0028.1166.
21. Findley R. Allen VM. Brock JK. Adverse Perinatal Conditions Associated With Prenatally Detected Fetal Echogenic Bowel in Nova Scotia. J Obstet Gynaecol Can. 2018;40(5):555-60. doi: 10.1016/j.jogc.2017.09.017.

22. Ameratunga DM. Said JM. Reidy K. Palma-Dias R. Perinatal outcomes following the ultrasound diagnosis of echogenic bowel: an Australian perspective. Fetal Diagn Ther. 2012;31(3):179-84. doi: 10.1159/000336123.

23. Ecevit Aİ. İnce DA. Kurt A. Tarcan A. Yanık F. Fetal Hyperechogenic Bowel and Early Necrotizing Enterocolitis in Three Intrauterine Growth Restricted, Extremely Low Birth Weight Infants. Perinat J 2011; 19(2):99-102.

24. Jessula S. Van Den Hof M. Mateos-Corral D. Mills J. Davies D. Romao RL. Predictors for surgical intervention and surgical outcomes in neonates with cystic fibrosis. J Pediatr Surg. 2018;53(11):2150-4. doi: 10.1016/j.jpedsurg.2018.05.016.

25. Bleu G. Coulon C. Vaast P. Bourgeot P. Sfeir R. Boute O. et al. Hyperechogenic fetal bowel: Which fetal and neonatal outcome? A French study of 149 cases. J Gynecol Obstet Biol Reprod (Paris). 2015;44(6):558-64. doi: 10.1016/j.jgyn.2014.08.004.

26. Kazandi M. Turan V. Selvi Demirtas G. Akercan F. Aykut A. Ozkinay F. Mid-trimester hyperechogenic bowel in a fetus of Turkish origin carrying a rarely seen mutation of cystic fibrosis. Arch Iran Med. 2012;15(7):449-51.

27. Scotet V. Dugueperoux I. Audrezet MP. AudebertBellanger S. Muller M. Blayau M. et al. Focus on cystic fibrosis and other disorders evidenced in fetuses with sonographic finding of echogenic bowel: 16-year report from Brittany, France. Am J Obstet Gynecol. 2010;203 (6):592 e1-6. doi: 10.1016/j.ajog.2010.08.033.

28. Egic A. Mikovic Z. Mandic V. Karadzov N. Prenatal diagnosis of meconium ileus and meconium peritonitis: indications for cystic fibrosis testing. Srp Arh Celok Lek. 2011;139(7-8):527-30. doi: 10.2298/sarh1108527e.

29. Saha E. Mullins EW. Paramasivam G. Kumar S. Lakasing L. Perinatal outcomes of fetal echogenic bowel. Prenat Diagn. 2012;32(8):758-64. doi: 10.1002/pd.3898.

30. Petrikovsky B. Smith-Levitin M. Holsten N. Intra-amniotic bleeding and fetal echogenic bowel. Obstet Gynecol. 1999;93(5 Pt 1):684-6. doi:10.1016/s0029-7844(98) 00528-6. 